\title{
WHAT IS THE RELEVANCE BETWEEN NORMAL BREATHING RATE AND TENDENCY TO DO EXERCISE?
}

\author{
MUHAMMAD IMRAN QADIR ${ }^{\mathrm{a}}$ AND HIRA ASIF ${ }^{\mathrm{b} 1}$ \\ ${ }^{\mathrm{ab}}$ Institute of Molecular Biology and Biotechnology, Bahauddin Zakariya University, Multan, Pakistan
}

\begin{abstract}
The resolution of exploration was that what is the relevance between normal breathing rate and tendency to do exercise. 130 scholars of Bahauddin Zakariya University, Multan, Pakistan attached with us to give significant outcomes. The task of alluring fresh air (oxygen) in the thoracic cavity and eliminating air (carbon dioxide) is designated as Breathing. Up taking oxygen is obligatory for aerophilic creatures for cellular respiration. This procedure is carried out for the catabolism of food to generate power. Sum of breaths taken in 60 seconds is labeled as Breathing Rate. Anti-depressing and anti-aging gesticulation due to body motion is named as Exercise. Breathing rate was observed by laying down novice on a bed. Setting stop watch to 60 second, individuals were loosened, and time was on. The elevation and depression in the chest were observed and number of times it occurred in 60 seconds was recorded. A questionnaire was manually manufactured and given to them. It was about the relevance of normal breathing rate with tendency to do exercise. It was summarized that there is no relevance between normal breathing rate and tendency to do exercise.
\end{abstract}

KEYWORDS: Motion, Breathing Rate

The task of alluring fresh air (oxygen) in the thoracic cavity and eliminating air (carbon dioxide) is designated as Breathing. Up taking oxygen is obligatory for aerophilic creatures for cellular respiration. This procedure is carried out for the catabolism of food to generate power. Sum of breaths taken in 60 seconds is labeled as Breathing Rate. Ordinary breathing rate ranges between 12 to 20 times of breath per minute. The enhancing and depressing phenomena of chest cavity stipulate breathing times in 60 seconds. Rapid breaths with struggling are tagged as Hyperventilation. Individual may be victim of this state when being a patient of heart disorders, asthma or nervous destruction. A rapid depressing rate is labeled as Bradypnea primly due to consumption of drugs. Breath is taken through nose (or mouth in some cases).

Anti-depressing and anti-aging gesticulation due to body motion is named as Exercise. It is done by variety of ways either merely walking or vigorously shaping your body. Due to modern era of technology we have become inert. We are unable to nourish our body and organs with fresh oxygen up take by releasing sweat. The only way we can do it is by exercise. Individuals of previous times were cool enough to withstand the hardships for their wise and salubrious life. Obligations for thirty-five minutes of normal walk is to remain enthusiastic for future.
The resolution of exploration was that what is the relevance between normal breathing rate and tendency to do exercise.

\section{MATERIALS AND METHODS}

130 scholars of Bahauddin Zakariya University, Multan, Pakistan attached with us to give significant outcomes.

\section{Breathing Rate}

Breathing rate was observed by laying down novice on a bed. Setting stop watch to 60 second, individuals wereloosened, and time was on. The elevation and depression in the chest were observed and number of times it occurred in 60 seconds was recorded.

\section{Project Design}

A questionnaire was manually manufactured and given to them. It was about the relevance of normal breathing rate with tendency to do exercise.

\section{Statistical Analysis}

M. software was utilized to interpret the data while considering $p<0.1$ significant with the application of $t$-test.

\section{RESULTS AND DISCUSSION}

Aggregation of our investigation were configured as tables. 0.30 was greater than 0.1 making non-significant

${ }^{1}$ Corresponding author 
outcomes in table 1. In table 2 upshots were observed nonsignificant. For table 3 the calculations were giving nonsignificant results. So, all three tables were presenting nonsignificant results.

Table 1: What is the relevance between normal breathing rate and tendency to do exercise?

\begin{tabular}{|c|c|c|}
\hline Parameters & Half Hour & 1 Hour \\
\hline MEAN & 20.86 & 23.38 \\
\hline SD & 7.16 & 7.88 \\
\hline$p$ - Value & $0.30^{\text {ns }}$ & \\
\hline
\end{tabular}

ns= non-significant

Table 2: What is the relevance between normal breathing rate and tendency to do exercise?

\begin{tabular}{|c|c|c|}
\hline Parameters & 1 Hour & 1 and half Hour \\
\hline MEAN & 23.38 & 25.33 \\
\hline SD & 7.88 & 5.18 \\
\hline$p$ - Value & $0.67^{\text {ns }}$ & \\
\hline
\end{tabular}

ns= non-significant

Table 3: What is the relevance between normal breathing rate and tendency to do exercise?

\begin{tabular}{|c|c|c|}
\hline Parameters & Half Hour & $\begin{array}{c}1 \text { and a half } \\
\text { Hour }\end{array}$ \\
\hline MEAN & 20.86 & 25.33 \\
\hline SD & 7.16 & 5.18 \\
\hline$p$ - Value & $0.34^{\text {ns }}$ & \\
\hline \multicolumn{3}{|c|}{$\mathbf{n s}=$ non-significant }
\end{tabular}

These questionnaire-based examinations presented consequential outcome for future research. These will be beneficial for upcoming research phenomenon of nature.

\section{CONCLUSION}

It was summarized that there is no relevance between normal breathing rate and tendency to do exercise.

\section{REFERENCES}

Daly W.J. and Bondurant S., 1962. Effects of oxygen breathing on the heart rate, blood pressure, and cardiac index of normal men-resting, with reactive hyperemia, and after atropine. The Journal of clinical investigation, 41(1):126-132.

Narkiewicz K., Van De Borne P., Montano N., Hering D., Kara T. and Somers V.K., 2006. Sympathetic neural outflow and chemoreflex sensitivity are related to spontaneous breathing rate in normal men. Hypertension, 47(1):51-5.

Qadir M.I. and Javid A., 2018. Awareness about Crohn's Disease in biotechnology students. Glo. Adv. Res. J. Med. Medical Sci., 7(3): 62-64.

Qadir M.I. and Javid A., 2018. Awareness about ischemic heart disease in university biotechnology students. Glo. Adv. Res. J. Med. Medical Sci., 7(3): 59-61.

Qadir M.I. and Ishfaq S., 2018. Awareness about hypertension in biology students. Int. J. Mod. Pharma Res., 7(2): 08-10.

Qadir M.I. and Mehwish, 2018. Awareness about psoriasis disease. Int. J. Mod. Pharma Res., 7(2): 17-18.

Qadir M.I. and Shahzad R., 2018. Awareness about obesity in postgraduate students of biotechnology. Int. J. Mod. Pharma Res., 7(2): 14-16.

Qadir M.I. and Rizvi M., 2018. Awareness about thalassemia in post graduate students. MOJ Lymphology \& Phlebology, 2(1): 14-16.

Qadir M.I. and Ghalia B.A., 2018. Awareness survey about colorectal cancer in students of $M$. Phil Biotechnology at Bahauddin Zakariya University, Multan, Pakistan. Nov Appro in Can Study, 1(3): NACS.000514.2018.

Qadir M.I. and Saba G., 2018. Awareness about intestinal cancer in university student. Nov Appro in Can Study, 1(3): NACS.000515.2018. 